\title{
Effects of Hypoxia and Reoxygenation on Regular Contractions and Postrest Contraction in Rat Papillary Muscles
}

\author{
Tetsuya TAtsumi, M.D., Jun Asayama, M.D., \\ Yasuhiro Yamahara, M.D., Hiroshi Miyazaki, M.D., \\ Miho Inoue, M.D., Itsuki Omori, M.D., \\ Daisuke Inoue, M.D., and Masao Nakagawa, M.D.
}

\section{Summary}

The effects of hypoxia and reoxygenation on regular contractions and postrest contractions (PRC) of papillary muscle of rats were studied. Isometric tension was measured during two cycles of hypoxia and reoxygenation. Trains of 80 externally continuous stimulations at $40 / \mathrm{min}$ were applied. PRCs were evoked by a stimulus train after a $60 \mathrm{sec}$ resting interval.

After 90 min of hypoxia (the first hypoxia period), regular contractions and PRCs decreased to $5.6 \pm 2.0 \%$ and $23.4 \pm 2.4 \%$ of baseline values, respectively $(\mathrm{p}<0.001 ; \mathrm{n}=18)$. After $90 \mathrm{~min}$ of reoxygenation, the recovery of the PRCs $(44.4 \pm 3.4 \%)$ was better than that of the regular contractions $(23.3 \pm 3.3 \%)(\mathrm{p}<0.01 ; \mathrm{n}=18)$. After $30 \mathrm{~min}$ of hypoxia (the second hypoxic period), regular contractions and PRCis decreased to $2.2 \pm 0.6 \%$ and $13.6 \pm 1.6 \%$ of baseline values, respectively $(\mathrm{p}<0.001$; $\mathrm{n}=18$ ). However, the recovery from the second hypoxic injury was not significant for either regular contractions or PRCs. The \% diastolic tension, which was normalized to the baseline for regular contractions, increased to $113.2 \pm 6.9 \%$ and $133.6 \pm 8.4 \%$ at the end of the first and the second hypoxic periods, respectively. There was statistically significant correlation between the \% diastolic tension and the $\%$ hypoxic injury of PRCs $(p<0.002 ; n=18)$. There was no significant relationship between $\%$ diastolic tension and $\%$ hypoxic injury of regular contractions. There was no statistically significant correlation between \% diastolic tension and \% recovery from the hypoxic injury of either regular contractions or PRCs.

Since the PRGs are thought to be more dependent on calcium stored in the sarcoplasmic reticulum (SR) than regular contractions, SR function seems to be resistant to transient hypoxia. The marked increase in diastolic tension during repeated hypoxia may indicate SR dysfunction, Japan.

From the Second Department of Medicine, Kyoto Prefectural University of Medicine, Kyoto,

Mailing address: Jun Asayama, M.D., Second Department of Medicine, Kyoto Prefectural University of Medicine, Kawaramachi-Hirokoji, Kamikyo-ku, Kyoto 602, Japan.

Received for publication September 10, 1990.

Accepted October 9, 1990. 
leading to irreversible myocardial damage. Thus, both hypoxia and reoxygenation may regulate the recovery from hypoxic dysfunction.

Additional Indexing Words:

Hypoxia Reoxygenation Postrest contraction (PRC) Papil-

lary muscle Rat

\begin{abstract}
brief transient occlusion of a coronary artery does not result in myocyte A necrosis. However, the contractile function of the viable myocardium is depressed for hours to days after restoration of blood flow. This phenomenon has come to be known as myocardial stunning. ${ }^{1)}$ Despite its clinical importance, the physiological features of the stunned myocardium are not well characterized and the mechanisms underlying depressed function have not been resolved.

It is well known that there is substantial variation in the ratio of cardiac sarcoplasmic reticulum (SR) calcium release to transsarcolemmal calcium influx in different species. ${ }^{2-4)}$ It has been suggested that the relative contribution of SR calcium release to tension development in rat ventricle is large. ${ }^{2)}$
\end{abstract}

The first potentiated contraction, elicited by restimulation after a rest period, has been called a postrest contraction $(\mathrm{PRG}){ }^{5}$ ) It is now known that $\mathrm{PRC}$ is mostly dependent on the $\mathrm{Ca}^{2+}$ in $\mathrm{SR}^{\left.{ }^{6}\right)}$ In this study hypoxia and reoxygenation were repeated in rat papillary muscles and PRCs were measured as an assay of SR function. The purpose of this study was to clarify the contributions of the SR to hypoxic injury and the stunned myocardium, and to determine whether hypoxic dysfunction regulates reoxygenation dysfunction.

\title{
Methods
}

\section{Tissue preparation:}

Male and female Wistar rats, weighing 250-300 g were used. ${ }^{6}$ The heart was quickly removed under urethane anesthesia $(100 \mathrm{mg} / 100 \mathrm{~g}$ body weight), and placed in normal physiologic saline containing $\mathrm{NaCl}$ (115.3 $\mathrm{mM}), \mathrm{KCl}(2.5 \mathrm{mM}), \mathrm{Na}_{2} \mathrm{HPO}_{4}(1.55 \mathrm{mM}), \mathrm{NaH}_{2} \mathrm{PO}_{4}(1.55 \mathrm{mM}), \mathrm{CaCl}_{2}$ $(1.8 \mathrm{mM})$, and tubocurarine chloride $(0.013 \mathrm{mM})$. Papillary muscles (1$2 \mathrm{~mm}$ in diameter) were removed from the right ventricles and mounted in a $2 \mathrm{ml}$ chamber with one end fixed and the other end connected to an isometric tension transducer (NEC, model ME-4021) with surgical silk. Muscles were stretched to approximately 1.2 times their resting length. 


\section{Solution:}

The control superfusate was a modified Tyrode's solution containing $\mathrm{NaGl}(136.9 \mathrm{mM}), \mathrm{KCl}(4.0 \mathrm{mM}), \mathrm{CaCl}_{2}(1.8 \mathrm{mM}), \mathrm{MgCl}_{2}(1.0 \mathrm{mM})$, $\mathrm{NaH}_{2} \mathrm{PO}_{4}(0.33 \mathrm{mM}), \mathrm{Na}_{2} \mathrm{HPO}_{4}(2.44 \mathrm{mM})$, glucose $(5.5 \mathrm{mM})$. This solution had been prewarmed to $30^{\circ} \mathrm{C}$ and bubbled with $100 \% \mathrm{O}_{2}$ before entering the chamber. The hypoxic solution was prepared by bubbling the glucosefree Tyrode solution with $100 \% \mathrm{~N}_{2}$. The $\mathrm{pH}$ was maintained at 7.4 in both solutions.

\section{Stimulation and recording:}

Muscles were stimulated by passing $5 \mathrm{~V}$ pulses of $2 \mathrm{msec}$ duration (Cardiac stimulator BC-02A, Fukuda Denshi); they were driven at $40 / \mathrm{min}$ for $60 \mathrm{~min}$ to obtain steady-state twitch tensions and isometric tension was recorded (Pen recorder VP-6513A, Panasonic Electronic).

\section{Regular contractions and PRCs:}

After an equilibration period of at least $60 \mathrm{~min}$ in the control solution, a train of 80 regular stimulations was delivered to the preparation, followed by a resting interval of $60 \mathrm{sec}$. The $\mathrm{PRC}$ sere then elicited by stimulations. Muscles remained mounted for $90 \mathrm{~min}$ in the hypoxic solution (the first hypoxic period) and were superfused with the reoxygenated control solution in the presence of glucose (the first reoxygenation period). The muscles

\section{$\begin{array}{lll}\text { (1) Normoxia (2) Hypoxia } & \text { (3) Reoxygenation }\end{array}$ \\ (Baseline)}

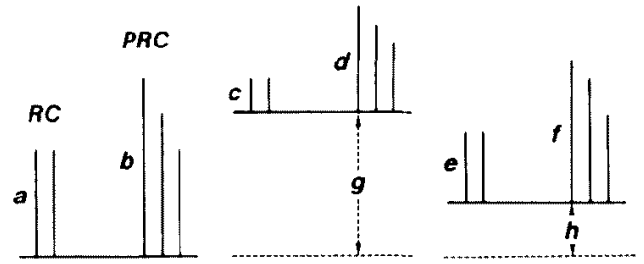

Fig. 1. Definition of \% hypoxic injury to regular contractions or PRCs, $\%$ recovery from hypoxic injury of regular contractions or PRCs, and \% diastolic tension.

Regular contractions: $a, c, e$; PRCs: b, d, f; Diastolic tension: $g$, h.

1) $\%$ Hypoxic injury to regular contractions $(\%):(a-c) / a \cdot 100$

2) \% Hypoxic injury to PRCs $(\%):(b-d) / b \cdot 100$

3) $\%$ Recovery from hypoxic injury of regular contractions $(\%):(e-c)$ $(a-c) \cdot 100$

4) $\%$ Recovery from hypoxic injury of PRCs $(\%)$ : (f $-d) /(b-d) \cdot 100$

5) $\%$ Diastolic tension $(\%):(\mathrm{g} / \mathrm{a}) \cdot 100,(\mathrm{~h} / \mathrm{a}) \cdot 100$ 
were then superfused for $30 \mathrm{~min}$ with the hypoxic solution (the second hypoxic period), and were superfused a second time with the reoxygenated control solution in the presence of glucose (the second reoxygenation) in order to clarify the effects of hypoxia and reoxygenation on regular contractions and PRCs.

One $\mu \mathrm{M}$ noradrenaline was applied in another group of 5 muscle preparations after the first reoxygenation period $(90 \mathrm{~min})$ and in a third group of 4 muscle preparations after the second reoxygenation period (90 min) to assess whether the muscles can be utilized as a model of stunned myocardium.

Data analysis and measurement:

All data were analyzed statistically using Student's t-test for paired data. $\%$ Hypoxic injury and \% recovery from hypoxic injury for regular contraction and PRC are defined in Fig. 1.

\section{Results}

Representative recordings of regular contractions and PRCs during the first hypoxic and reoxygenation periods are shown in Fig. 2. Hypoxia induced a marked decrease in regular contractions, a moderate decrease in PRCs, and an increase in diastolic tension. Reoxygenation induced a moderate recovery of both regular contractions and $\mathrm{PRCs}$, and a decrease in diastolic tension.

Noradrenaline $(1 \mu \mathrm{M})$ was applied after the first reoxygenation period. Noradrenaline significantly augmented the magnitude of regular contractions from $37.4 \pm 11.9 \%$ of baseline measurements to $53.0 \pm 16.9 \% \quad(p<0.05$; $\mathrm{n}=5$ ). However, noradrenaline did not affect the magnitude of regular contraction after the second reoxygenation period (from $10.1 \pm 2.2 \%$ to $10.3 \pm$ $2.5 \% ; \mathrm{n}=4, \mathrm{NS}$ ).

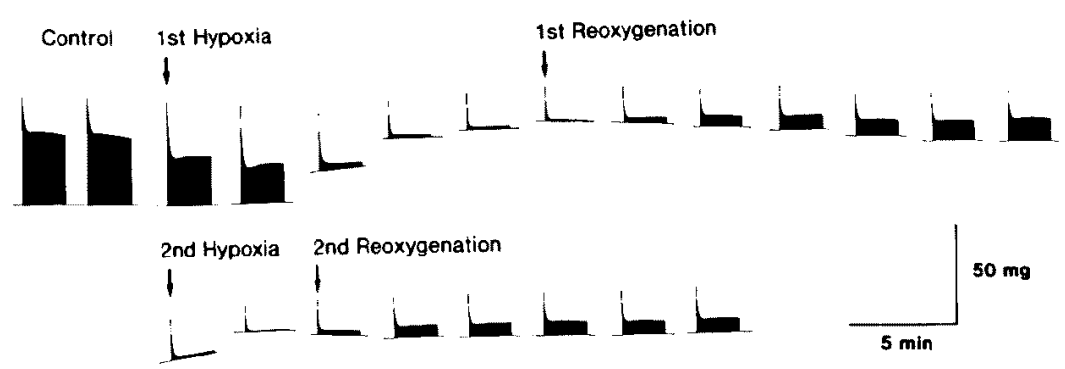

Fig. 2. Influences of hypoxia and glucose elimination for $90 \mathrm{~min}$ and reoxygenation for 90 min on regular contractions and PRCs. Recordings from one papillary muscle are shown. 
The statistical analyses of relative changes in regular contractions, PRCs, and \% diastolic tension during hypoxia and reoxygenation are shown in Fig. 3. At the end of the first hypoxic period regular contractions and PRCs decreased to $5.6 \pm 2.0 \%(n=18)$ and $23.4 \pm 3.3 \%(n=18)$ of baseline, respectively. At the end of the first reoxygenation period, regular contractions and PRCs recovered to $23.3 \pm 2.4 \%(n=18)$ and $44.4 \pm 3.4 \%(n=18)$ of baseline values, respectively. At the end of the second hypoxic period, regular contractions and PRCs decreased to $2.2 \pm 0.6 \%(\mathrm{n}=18)$ and $13.6 \pm$ $1.6 \%(n=18)$ of baseline, respectively. At the end of the second reoxygenation period, though, they both recovered partially to $10.1 \pm 2.2 \%(\mathrm{n}=8)$ and $22.6 \pm 4.9 \% \quad(n=8)$ of baseline values, respectively. The \% diastolic tension increased to $113.2 \pm 6.9 \%(n=18)$ and $133.6 \pm 8.4 \%(n=8)$ at the end of the first and the second hypoxic periods, respectively. It is noteworthy that only 8 papillary muscles were analyzed after the second hypoxic and reoxygenation periods; the other 10 muscles were used for protocols which were not presented in this paper.

There was a statistically significant correlation between the $\%$ diastolic tension and the \% hypoxic injury of PRCs (first hypoxic period: $r=0.83$,

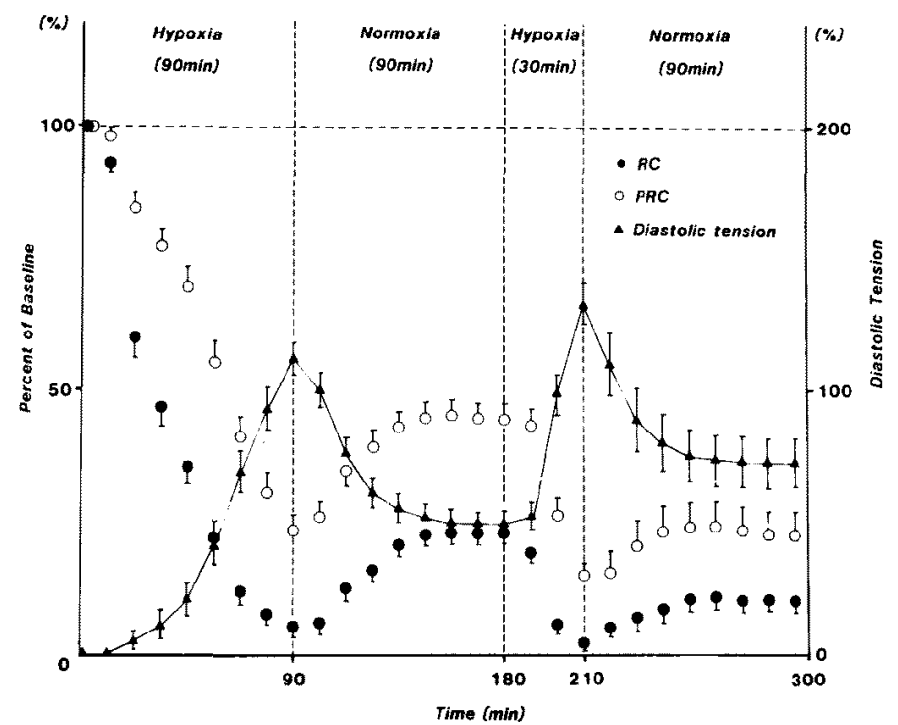

Fig. 3. The time course for the hypoxic and reoxygenation-induced changes in the magnitude of regular contractions-RC $(-)$, PRCs $(O)$, and $\%$ diastolic tension ( $\mathbf{\Lambda})$. All points $\mathrm{cxccpt}$ for the second reoxygenation period represent the mean of 18 experiments. Data during the second reoxygenation period represent the mean of 8 experiments; the vertical bars indicate SE. 

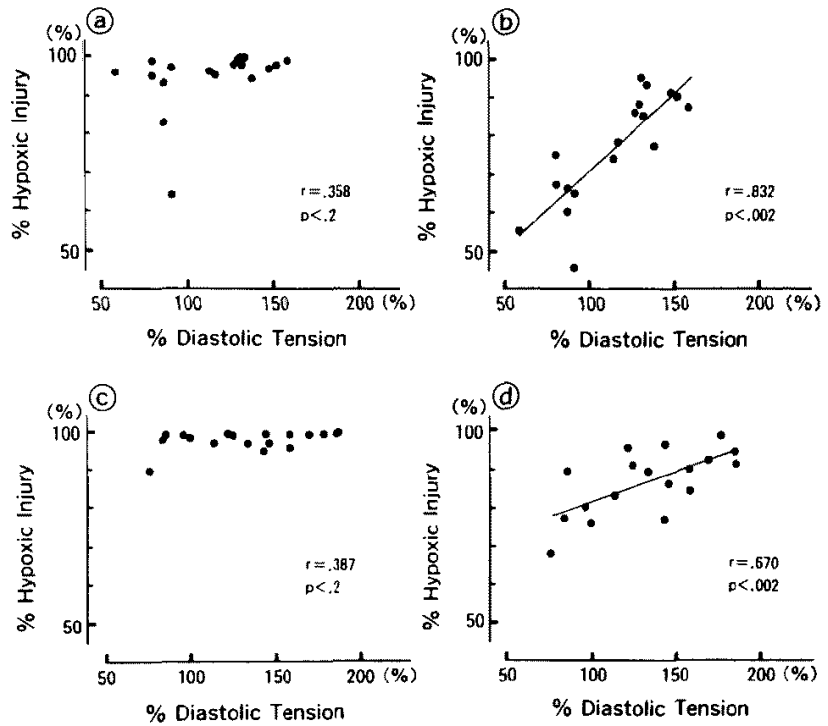

Fig. 4. The relationship between $\%$ diastolic tension and \% hypoxic injury of regular contractions (a: the first hypoxic period; $c$ : the second hypoxic period) or PRCs (b: the first hypoxic period; $d$ : the second hypoxic period).
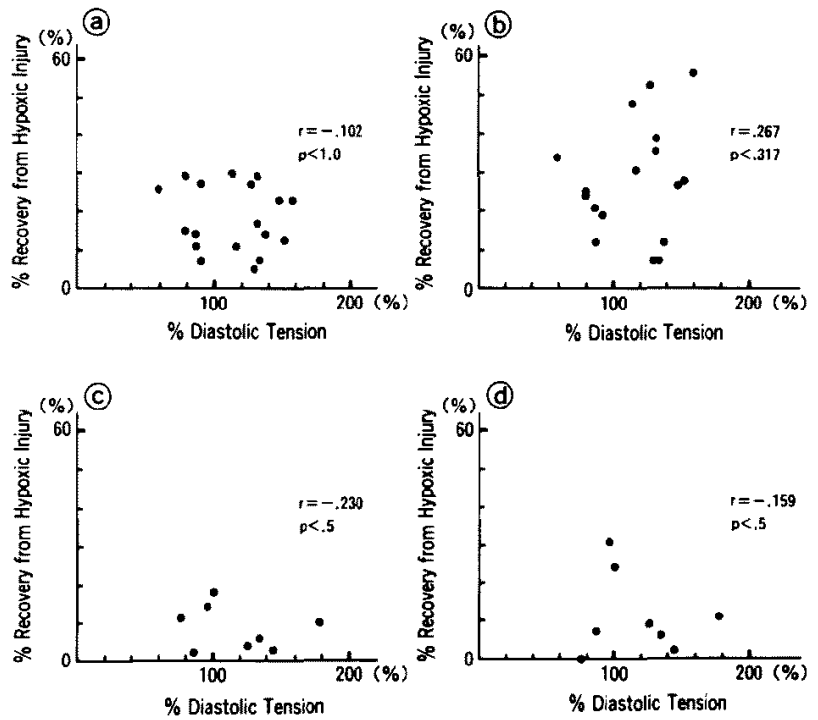

Fig. 5. The relationship between $\%$ diastolic tension and $\%$ recovery from hypoxic injury of regular contractions (a: the first hypoxic period; $c$ : the second hypoxic period) or PRCs (b: the first hypoxic period; $d$ : the second hypoxic period). 
$\mathrm{p}<0.002, \mathrm{n}=18$; second hypoxic period: $\mathrm{r}=0.67, \mathrm{p}<0.002, \mathrm{n}=18) . \quad \mathrm{A}$ significant correlation was not observed between the $\%$ diastolic tension and changes in regular contractions (Fig. 4). There was no statistically significant correlation between \% diastolic tension and \% recovery from hypoxic injury for either PRCs or regular contractions (Fig. 5).

\section{Discussion}

A rest period during the regular stimulation of isolated cardiac muscles causes a large transient augmentation of subsequent twitch tension, ${ }^{5}$ ) termed a PRC. The $\mathrm{Ca}^{2+}$ content of the SR reflects both cytoplasmic $\mathrm{Ca}^{2+}$ and extracellular $\mathrm{Ca}^{2+}$ entry into the cell. ${ }^{7), 8}$ It is well known that methylxanthines inhibit both PRCs and post-extrasystolic potentiation. ${ }^{9), 10)}$ Endoh et $a^{111}$ reported that calcium channel blockers significantly decreased the strength of regular contractions, but that PRCs were not significantly changed. It is now known that PRCs are mostly dependent on the $\mathrm{Ca}^{2+}$ content of SR. In the present study, we used PRCs to assess the functional status of the SR. ${ }^{7,8), 12)}$ A resting interval of $60 \mathrm{sec}$ was chosen because the maximum PRC is obtained with a $60-90 \mathrm{sec}$ resting interval at a basic cycle length of 1,500 msec. $^{6)}$

In this study regular contractions were depressed more markedly than PRCs during both the first and second hypoxic periods. These pieces of evidence suggest that the integrity of $\mathrm{SR} \mathrm{Ca}^{2+}$ reserves is resistant to hypoxia in rats, possibly reflecting the large calcium capacity of SR in these species. ${ }^{61}$

The amplitude of the diastolic tension is due mainly to residual $\mathrm{Ca}^{2+}$ myofilament interactions. These interactions reflect an increased intracellular $\mathrm{Ca}^{2+}$ content during diastole, which is usually regulated by the SR $\mathrm{Ca}^{2+}$ pump and sarcolemmal $\mathrm{Na}^{+}-\mathrm{Ca}^{2+}$ exchange mechanism. A rapid decline in developed tension during hypoxia has been attributed to a substantial increase in inorganic phosphate ${ }^{13}$ ) and a very large fall in $\mathrm{pH}$. It is now known that acidosis ${ }^{14}$ and free oxygen radicals ${ }^{15}$ ) decrease the rate of $\mathrm{Ca}^{2+}$ accumulation by the SR. In fact, ischemia causes impairment of $\mathrm{Ca}^{2+}$ uptake by the SR. ${ }^{16)}$ In this experiment, there was a significant correlation between the $\%$ diastolic tension and the $\%$ hypoxic injury of PRCs, while there was no relationship between \% diastolic tension and the \% hypoxic injury of regular contractions (Fig. 4). These results imply that the increase in cytoplasmic calcium during hypoxia may be derived mainly from the SR but not extracellular calcium. In other words, \% diastolic tension may represent the degree of inhibited SR function.

After the first reoxygenation period, the regular contractions were 
severely depressed to $20-25 \%$ of the baseline, while PRCs were depressed to approximately $45 \%$ of the baseline values (Fig. 3). Noradrenaline significantly augmented the magnitude of regular contractions after the first reoxygenation period. However, noradrenaline did not affect the magnitude of regular contractions after the second reoxygenation period. It is well known that catecholamines and calcium infusion improve the function of stunned myocardium. ${ }^{17)}$ Thus, the first reoxygenation period is comparable to the stunned myocardium and the myocardium appears to be injured irreversibly after the second reoxygenation period.

Recently, Kusuoka et $\mathrm{al}^{\left.18,{ }^{19}\right)}$ reported a paradoxical increase in $\mathrm{Ca}^{2+}$ transients in stunned myocardium. They suggested that contractile failure in stunned myocardium is due to a decrease in both the myofilament sensitivity to $\mathrm{Ca}^{2+}$ and maximal $\mathrm{Ca}^{2+}$-activated force. It is presently unclear whether the myocardium is "stunned" during ischemia or during reperfusion, since recovery is impossible without reoxygenation. Since there is no good correlation between $\%$ diastolic tension and \% recovery from hypoxic injury (Fig. 5), reperfusion injury may influence both regular contractions or PRGs. This implies that reoxygenation may induce SR dysfunction. ${ }^{15}$ From these findings, we suggest that both hypoxia and reoxygenation are factors that produce stunned myocardium.

The present study suggests that stunned myocardium deteriorates further during a second cycle of hypoxia and reoxygenation. Thus, residual myocardial function may be further injured by restenosis and reperfusion in vivo. We suspect that viability of the ischemic myocardium may depend on residual SR function.

\section{References}

1. Braunwald E, Kloner RA: The stunned myocardium: prolonged, post-ischemic ventricular dysfunction. Circulation 60: 1146, 1982

2. Bers DM: Ca influx and sarcoplasmic reticulum $\mathrm{Ca}$ release in cardiac muscle activation during postrest recovery. Am J Physiol 248: H366, 1985

3. Penefsky 7J: Studies on mechanism of inhibition of cardiac muscle contractile tension by ryanodine. Plügers Arch 347: 173, 1974

4. Sutko JL, Willerson JT: Ryanodine alteration of the contractile state of rat ventricular myocardium. Comparison with dog, cat, and rabbit ventricular tissues. Circ Res 46: 333, 1980

5. Frank M, Sleator WW: Effect of ryanodine on myocardial calcium. Naunyn-Schmiedeberg's Arch Pharmacol 290: 35, 1975

6. Tatsumi T, Asayama J, Miyazaki H, Shirayama T, Omori I, Inoue D, Nakagawa M: The role of an extra-stimulation on postextrasystolic potentiation in papillary muscles of rats. Jpn Heart J 31 : 355, 1990

7. Elzinga G, Lab MJ, Noble MIM, Papadoyannis DE, Pidgeon J, Seed A, Wohlfart B: The action-potential duration and contractile response of the intact heart related to the preceding 
interval and the preceding beat in the dog and cat. J Physiol 314: 481, 1981

8. Fabiato A: Simulated calcium current can both cause calcium loading in and trigger calcium release from the sarcoplasmic reticulum of a skinned canine cardiac Purkinje cell. J Gen Physiol 85: 291, 1985

9. Asayama J, Tatsumi $\mathbf{T}$, Omori I, Inoue D, Katsume $H$, Nakagawa $M$ : The contribution of an extrasystole to pustextrasystolic potentiation in papillary muscles of guinea pigs. Jpn Heart J 30: 411, 1989

10. Asayama J, Tatsumi T, Miyazaki H, Omori I, Inoue D, Nakagawa M: Suppressing effects of caffeine on postextrasystolic potentiation in papillary muscles of guinea pigs. Jpn Circ J 54: 207, 1990

11. Endoh M, Iijima $T$ : Twitch potentiation by rest in canine ventricular muscle. Am J Physiol 241: H583, 1981

12. Kerker JP, Ruigrok TJC, Nieuwenhuijs BHM, Borst C, Meijer FL: Post-extrasystolic potentiation: influence of calcium and verapamil in rat and rabbit hcarts. Eur Heart J 6: 532, 1985

13. Kentish JC: The effects of inorganic phosphate and creatine phosphate on force production in skinned muscles from rat ventricle. J Physiol 370: 585, 1986

14. Fabiato A, Fabiato $\mathrm{F}$ : Effects of $\mathrm{pH}$ on the myofilaments and the sarcoplasmic reticulum of skinned cells from cardiac and skeletal muscle. J Physiol 276: 233, 1978

15. Hess ML, Okabe E, Ash P, Kontos HA: Free radical mediation of the effects of acidosis on calcium transport by cardiac sarcoplasmic reticulum in whole heart homogenates. Cardiovasc Res 18: 149, 1984

16. Lee KS, Ladinsky H, Stuckey JH: Decreased $\mathrm{Ca}^{2+}$ uptake by sarcoplasmic reticulum after coronary artery occlusion for 60 and 90 minutes. Circ Res $21: 439,1967$

17. Allen DG, Jewell BR, Wood EH: Studies of the contractility of mammalian myocardium at low rates of stimulation. J Physiol 254: 1, 1976

18. Kusuoka H, Porterfield JK, Weisman HF, Weisfeldt ML, Marban E: Pathophysiology and pathogenesis of stunned myocardium. J Clin Invest 79: 950, 1987

19. Kusuoka H, Koretsune Y, Chacko VP, Weisfeldt ML, Marban E: Excitation-contraction coupling in postischemic myocardium: Does failure of activator $\mathrm{Ca}^{2+}$ transients underlie stunning? Circ Res 66: 1268, 1990 